\title{
Analysis of the Metabolites of Indole Degraded by an Isolated Acinetobacter pittii L1
}

\author{
Zuoyi Yang, Junhui Zhou, Yanbin Xu, Yaping Zhang, Haien Luo, \\ KenLin Chang, and Yujie Wang \\ School of Environmental Science and Engineering, Guangdong University of Technology, Guangzhou 510006, China \\ Correspondence should be addressed to Junhui Zhou; cms5211110@mail2.gdut.edu.cn
}

Received 27 August 2017; Accepted 19 November 2017; Published 13 December 2017

Academic Editor: Shijian Ge

Copyright (C) 2017 Zuoyi Yang et al. This is an open access article distributed under the Creative Commons Attribution License, which permits unrestricted use, distribution, and reproduction in any medium, provided the original work is properly cited.

\begin{abstract}
Indole and its derivatives are typical nitrogen heterocyclic compounds and have been of immense concern since they are known for the risk of their toxic, recalcitrant, and carcinogenic properties for human and ecological environment. In this study, a Gramnegative bacterial strain of eliminating indole was isolated from a coking wastewater. The strain was confirmed as Acinetobacter pittii L1 based on the physiological and biochemical characterization and 16S ribosomal DNA (rDNA) gene sequence homology. $400 \mathrm{mg} / \mathrm{L}$ indole could be completely removed within $48 \mathrm{~h}$ by the strain on the optimum condition of $37^{\circ} \mathrm{C}$, pH 7.4, and $150 \mathrm{rpm}$. The organic nitrogen was converted to $\mathrm{NH}_{3}-\mathrm{N}$ and then to $\mathrm{NO}_{3}{ }^{-}$and the organic carbon was partially transferred to $\mathrm{CO}_{2}$ during the indole biodegradation. The metabolic pathways were proposed to explain the indole degradation based on the liquid chromatography tandem mass spectrometry (LC-MS/MS) analysis of indigo, 4-(3-Hydroxy-1H-pyrrol-2-yl)-2-oxo-but-3-enoic acid, and isatin. The toxicity of the biodegradation products was evaluated using the Microtox test, which revealed that the metabolites were more toxic than indole. Our research holds promise for the potential application of Acinetobacter pittii L1 for NHCs degradation, production of indigoids, and soil remediation as well as treatment of indole containing wastewater.
\end{abstract}

\section{Introduction}

Indole and its derivatives, with highly toxic and carcinogenic properties, are mainly generated in large quantities as a result of industrial wastewater from pharmaceutical synthesis, fuel, cosmetics, pesticide, disinfectant, agrochemicals, and dyestuff and have recently gained wide attention [1-4]. These compounds also existed in large amounts of livestock manure emissions, which are serious pollution to the ecological environment with a sharp odor. Their heterocyclic structure makes them not only merely more soluble but also more difficult to degradation; therefore these cyclic compounds could be transformed through the soil and contaminated ground water.

Indole is a typical tryptophan metabolite in the natural environment, acting as plant hormone precursor and microbial signal molecule [5-7]. Furthermore, indole also acted as a gas pollutant because of its unfavorable odor, especially released from the pharmaceutical, coking, and livestock wastewater.
The technologies of contact glow discharge plasma degradation, photocatalytic degradation, and electro-Fenton oxidation were used to degrade indole, and the chemical oxidants such as chlorine and chlorine dioxide were used to control indole release $[8,9]$. The photocatalytic degradation and chemical oxidation can efficiently break up indole, but the high investment and energy consumption confined the engineering applications, and the chemical oxidants could induce new toxic and carcinogenic compounds $[8,10,11]$.

Some bacteria demonstrated their abilities of decomposing $\mathrm{N}$-heterocyclic compounds. For example, a novel endophytic fungus Phomopsis liquidambari could catalyze indole into 2-aminobenzoic acid and 2-dioxindole and an isolated strain Bacillus sp. from petroleum-contaminated soil was able to decompose quinoline under aerobic conditions [12, 13]. Bacteria from genera Alicycliphilus, Alcaligenes, and Thauera were thought to be responsible for indole degradation [4]. Moreover, $\mathrm{Qu}$ et al. indicated that a rich set of oxidoreductases was expressed from a newly isolated Cupriavidus 
sp. SHE, which might be the most important factor for the efficient indole degrading [14].

It was reported that the $\mathrm{C}-\mathrm{N}$ position of pyridine ring in indole and quinoline can be broken down by the microbe $[12,13]$. One of the indole metabolic pathways was known as the isatin pathway, in which indole was degraded via the formation of indoxyl, 2,3-dihydroxyindole, isatin, $\mathrm{N}$ formylanthranilic acid, anthranilic acid, salicylic acid, and catechol [15]. The other metabolic pathway was reported as the gentisate pathway, in which indole was degraded via indoxyl, isatin, anthranilic acid, and gentisate [16]. In this study, the metabolites were analyzed and the indole metabolic pathways of Acinetobacter pittii were illuminated.

The Microtox test was widely employed for evaluating the toxicity of the compounds and their products by using the prokaryote Vibrio fischeri. According to the Microtox test, Chen et al. indicated that the toxicity of the photoproducts of mefenamic acid were more toxic than their parent compounds [3]. Wang et al. analyzed the toxicity and mineralization of IDM under the conditions of AOPs; the results indicated that the inhibition rates of IDM declined dramatically in the presence of $1.0 \mathrm{~g} / \mathrm{L} \mathrm{NCDs} / \mathrm{g}-\mathrm{C}_{3} \mathrm{~N}_{4}$ [17]. According to compounds, the types of degradation, and the toxicity assay methods, we can find out that the toxicity of different contaminants might increase or decrease in different occasion.

Acinetobacter spp. has been applied in a wide range of fields such as pharmaceutical industry and soil remediation. Researchers demonstrated that Acinetobacter spp. could utilize phenol or 4-nitroaniline as the sole carbon source and remove PAHs [18-21]. Acinetobacter spp. was also reported to be able to degrade N-heterocyclic compounds [20, 22]. The effective biotechnology has been reported to optimize the indole removal rate $[15,22,23]$. The initial indole concentrations were usually controlled to be lower than $200 \mathrm{mg} / \mathrm{L}$ to prevent them from inhibiting the bacterial growth $[14,15]$.

In this study, we isolate a bacterial from a coking wastewater and investigate the degradation of indole; meanwhile, the metabolites were analyzed and the indole metabolic pathways of Acinetobacter pittii were illuminated and the toxicity changes about NHCs have also been detected.

\section{Materials and Methods}

2.1. Chemicals and Mediums. Indole (98.5\%), quinoline (99.5\%), and phenol (98\%) were purchased from Aladdin Industrial Co., Ltd. Pyridine (99\%) was purchased from Chengdu Kelong Chemical Reagent Co., Ltd. (Sichuan, China). High-performance liquid chromatography (HPLC) grade reagent methanol was obtained from Shanghai ANPEL Scientific Instrument Co., Ltd. (Shanghai, China). Ultrapure water from a Milli-Q apparatus (Smart2 Pure ultrapure water/ water system integration, TKA, Germany) was applied in the HPLC and LC-MS/MS. All the other reagents were of analytic grade or above.

The mineral salt medium (MSM medium) was used for the isolation and biodegradation, which contained $\left(\mathrm{g} \cdot \mathrm{L}^{-1}\right)$ : $\mathrm{K}_{2} \mathrm{HPO}_{4}, 0.8 ; \mathrm{KH}_{2} \mathrm{PO}_{4}, 0.2 ; \mathrm{CaCl}_{2}, 0.05 ; \mathrm{MgCl}_{2} \cdot \mathrm{H}_{2} \mathrm{O}, 1.07$; $\mathrm{FeCl}_{2} \cdot \mathrm{H}_{2} \mathrm{O}, 0.016 ;\left(\mathrm{NH}_{4}\right)_{2} \mathrm{SO}_{4}, 1.0 ; \mathrm{NaCl}, 5.0 ; \mathrm{pH}$ 7.0. The
Luria-Bertani medium (LB medium) contained $\left(\mathrm{g} \cdot \mathrm{L}^{-1}\right)$ : yeast extract, 5.0; peptone, $10 ; \mathrm{NaCl}, 5.0 ; \mathrm{pH}$ 7.0. All the media appending different indole concentration were autoclaved at $121^{\circ} \mathrm{C}$ for $30 \mathrm{~min}$, and $2.0 \%(w / v)$ agar was added in the corresponding solid medium.

2.2. Bacterial Isolation and Identification. The target microorganism came from the sludge in a coke quenching effluent treatment system. The initial sludge was inoculated into $100 \mathrm{~mL}$ sterilized MSM containing $50 \mathrm{mg} / \mathrm{L}$ indole and then cultivated at $37^{\circ} \mathrm{C}$ with $150 \mathrm{rpm}$ for $48 \mathrm{~h}$. To get the indoleacclimating bacteria, $10 \%(v / v)$ of the above culture was transferred into the MSM with the addition of indole ranging from 50 to $400 \mathrm{mg} / \mathrm{L}$ every other five days for a month. Finally, the isolated strain L1 was characterized by morphological, physiological, and biochemical identification.

With the help of the BLAST software, 16S rDNA gene sequence was used to explore the homological relationship of the isolated strain L1. 16S rDNA gene of the strain L1 was amplified by PCR with universal primer pair $8 \mathrm{~F}\left(5^{\prime}\right.$-AGA GTT TGA TCC TGG CTC AG- $3^{\prime}$ ) and 1492R ( $5^{\prime}$-GGT TAC CTT GTT ACG ACT T- $3^{\prime}$ ). The phylogenetic tree of the isolated strain was inferred by MEGA 5.1 software using neighbor-joining method with a bootstrap value of 1000 replicates.

2.3. Evaluation of Indole Biodegradation. The strain L1 was cultivated in $\mathrm{LB}$ medium $\left(37^{\circ} \mathrm{C}, 150 \mathrm{rpm}, 24 \mathrm{~h}\right)$; the cells in logarithmic growth phase were collected and then centrifuged at $6000 \times \mathrm{g}$ for $10 \mathrm{~min}$ (TDL-60B, Anting Scientific Instrument, Shanghai, China). Remove the medium and wash the pellet with PBS, and then resuspend the cell pellet to make $\mathrm{OD}_{600}=1$. The suspension was used immediately in the biodegradation experiments. To further investigate its capability of degrading indole, the removal rate at the different initial indole concentrations, temperatures, and $\mathrm{pH}$ values were analyzed by HPLC. The removal rates of pyridine, quinoline, and phenol, which are the typical compounds in the coking wastewater, were also tested when they acted as the sole carbon source in MSM medium inoculated Acinetobacter pittii L1. All samples were measured in triplicate. Moreover, the removal efficiency (RE) of indole was calculated with the equation $\mathrm{RE}(\%)=\left(C_{0}-C_{t}\right) / C_{0} \times 100 \%$, in which $C_{0}$ and $C_{t}$ are the initial and residual concentration.

2.4. Analytical Methods. The concentration of indole was detected by HPLC that contains a Shimadzu SPD-M20A photodiode array detector and two Shimadzu LC-20AD pumps (Shimadzu, Japan). The HPLC was equipped with a Zorbax Eclipse XDB-C18 column $(2.1 \mathrm{~mm} \times 150 \mathrm{~mm}, 3.5 \mu \mathrm{m})$ and the mobile phase was composed of methanol: water $(70: 30 \mathrm{v} / \mathrm{v})$ at $40^{\circ} \mathrm{C}$, with the flow rate of $0.2 \mathrm{~mL} \cdot \mathrm{min}^{-1}$. Total organic carbon (TOC) was measured by Shimadzu (TOC-VCPH). UV spectrophotometer (UV-2100, Beijing Rayleigh) was utilized to determine the concentration of pyridine, quinoline, and phenol at $257 \mathrm{~nm}, 313 \mathrm{~nm}$, and $280 \mathrm{~nm}$, respectively. Ammonia nitrogen determination was detected by Nessler's reagent spectrophotometry. 
In order to elucidate the possible indole degradation pathways, the metabolites of indole biodegradation were analyzed by LC-MS/MS, consisting of an Agilent 1100 series HPLC coupled to a 6410 triple quadrupole mass spectrometer (Agilent Technologies, USA). Acinetobacter pittii L1 was inoculated $(5 \% v / v)$ into MSM including $200 \mathrm{mg} / \mathrm{L}$ indole and cultivated on the optimum conditions for $24 \mathrm{~h}$. Then the culture was centrifuged at $6000 \times \mathrm{g}$ for $10 \mathrm{~min}$; the supernatant was filtered by $0.22 \mu \mathrm{m}$ micropolyether sulfone (PES) membrane syringe filter (Jinteng Experimental Equipment Co., Ltd. Tianjin). The solution was then transferred to a sample vial for characterization by LC-MS/MS. Separation was accomplished using an Agilent SB-C18 column $(4.6 \times 150 \mathrm{~mm}$, $5 \mu \mathrm{m})$. The eluent was made up of the ultrapure water (A) and methanol (B) at the flow rate of $1 \mathrm{~mL} \cdot \mathrm{min}^{-1}$. An autosampling device was employed to inject the sample which was detected at $270 \mathrm{~nm}$. The elution was analyzed by the UV-vis detector of a mass spectral equipped with electrospray ionization (ESI) under negative mode. A mass full scan was conducted over a range of $50-550 \mathrm{~m} / \mathrm{z}$ to identify the intermediates in the indole biodegradation, and the operation parameters were as follows: capillary voltage $3.5 \mathrm{kV}$, fragmentor $125 \mathrm{~V}$, temperature $350^{\circ} \mathrm{C}$, nebulizer pressure $30 \mathrm{psi}$, and nitrogen as the desolvation gas.

The samples were collected after every 3 hours of biodegradation of $100 \mathrm{mg} / \mathrm{L}$ indole solution, which was degraded by Acinetobacter pittii $\mathrm{L} 1$ at $37^{\circ} \mathrm{C}$ with $150 \mathrm{rpm}$ for $24 \mathrm{~h}$. Then Microtox Model DXY-2 was employed to determine the toxicity of samples and initial indole solution, which evaluates the ability of the metabolites to inhibit the bioluminescence of the strain $V$. fischeri. According to the equation $I(\%)=$ $\left(I_{0}-I_{t}\right) / I_{0} \times 100 \%$, the inhibition of $V$. fischeri can be calculated.

\section{Results and Discussion}

3.1. Microorganism Isolation and Identification. The strain L1 was isolated from the sludge in a facultative coke quenching tank. The growth curve of the strain and the indole remove rate in MSM were shown in Figure $1.100 \mathrm{mg} / \mathrm{L}$ indole could be completely removed within $15 \mathrm{~h}$, showing the better degradation efficiency compared with Phomopsis liquidambari (degrading efficiency $41.7 \%, 100 \mathrm{mg} / \mathrm{L}$ indole in $120 \mathrm{~h}$ ) and Pseudomonas aeruginosa Gs (degrading $1.0 \mathrm{mM}$ indole in $36 \mathrm{~h}$ ) $[13,24]$. As depicted in Figure 1, the bacteria were in logarithmic growth phase, $\mathrm{OD}_{600}$ increased with increasing biomass in 6-12 h. Therefore, the efficiency of indole degradation was improved dramatically.

The isolated strain L1 was a short rod-shaped, Gramnegative aerobe, and the physiological and biochemical properties were shown in Table 1. 16S rDNA gene sequence was applied to confirm the phylogeny relationships, and the strain was nominated as Acinetobacter pittii L1, which showed 99\% gene sequence similarity with Acinetobacter pittii ATCC19004 (GenBank accession number: NR117621). Figure 2 showed the phylogenetic tree correlated to the other species from the NCBI GenBank database by the method of neighbor-joining on the program MEGA 5.1.

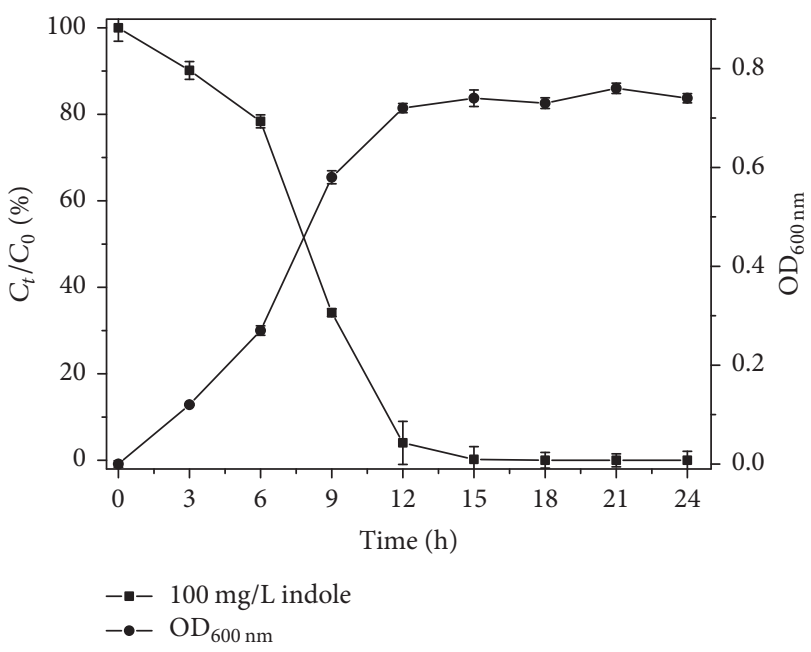

FIGURE 1: Growth curve of Acinetobacter pittii L1 and the change of indole concentration.

TABLE 1: Biochemical characteristics of Acinetobacter pittii L1.

\begin{tabular}{lc}
\hline Biochemical and culture conditions & Results \\
\hline Gram-staining & - \\
Anaerobic growth & - \\
Glucose utilization & - \\
Catalase & + \\
Oxidase & - \\
Citrate utilization & + \\
V-P test & - \\
Gelatin liquefaction & - \\
Hydrogen sulfide test & - \\
Hydrolysis of starch & - \\
MR test & - \\
\hline
\end{tabular}

+: positive reaction; -: negative reaction.

\subsection{Major Parameters Affecting the Biodegradation}

3.2.1. Initial Concentration. When the initial indole concentration ranged from 100 to $400 \mathrm{mg} / \mathrm{L}$, indole could be completely degraded within $48 \mathrm{~h}$ on the condition of $37^{\circ} \mathrm{C}$, $\mathrm{pH}$ 7.0, and $150 \mathrm{rpm}$. As shown in Figure 3(a), the higher the initial indole concentration is, the smaller the removing rate of indole is. $\mathrm{Qu}$ et al. also reported the inhibited effect of indole to the stain SHE; for example, $50-100 \mathrm{mg} / \mathrm{L}$ indole could be completely degraded within $24 \mathrm{~h}$, but $200 \mathrm{mg} / \mathrm{L}$ indole should be removed within $80 \mathrm{~h} \mathrm{[14]}$.

3.2.2. Temperature. The temperature was essential and sensitive to the microbe growth and the enzyme catalysis [25]. As shown in Figure 3(b), $200 \mathrm{mg} / \mathrm{L}$ indole was degraded by the strain $\mathrm{Ll}$ at $\mathrm{pH} 7.0$ and $150 \mathrm{rpm}$ for $48 \mathrm{~h}$. The indole removal rates were determined as $54.81 \%, 97.36 \%, 100 \%, 74.07 \%$, and $14.87 \%$, respectively, at $25^{\circ} \mathrm{C}, 30^{\circ} \mathrm{C}, 37^{\circ} \mathrm{C}, 45^{\circ} \mathrm{C}$, and $50^{\circ} \mathrm{C}$. Therefore, Acinetobacter pittii $\mathrm{L} 1$ showed the optimum temperature to degrade indole at $37^{\circ} \mathrm{C}$ in this study, compared with white rot fungus at $25^{\circ} \mathrm{C}$, Phomopsis liquidambari 


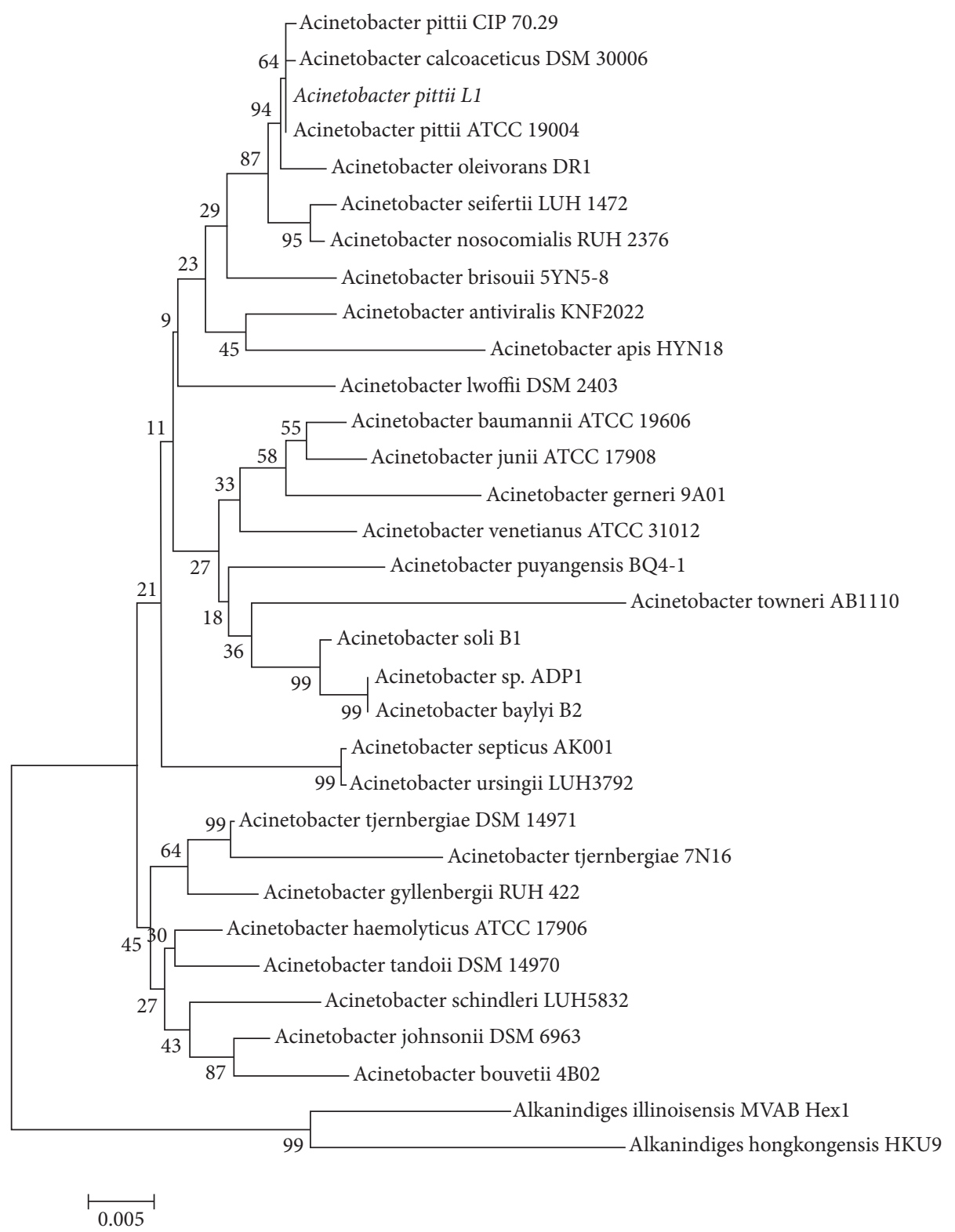

Figure 2: Phylogenetic tree of the strain L1 based on $16 \mathrm{~S}$ rDNA analysis with the neighbor-joining method of the program MEGA 5.1. The numbers shown next to the nodes indicated the bootstrap values of 1000 for the confidence level.

at $28^{\circ} \mathrm{C}$, Ps aeruginosa and Bacillus sp. at $30^{\circ} \mathrm{C}[12,13$, $24,26]$, and the fungus Sporotrichum thermophile at $45^{\circ} \mathrm{C}$ [23].

3.2.3. $p H$ Value. It was shown in Figure 3(c) that indole could be degraded by the strain $\mathrm{L} 1$ at $\mathrm{pH} 6.0,7.0$, and 8.0 at $36 \mathrm{~h}$, and the indole removal rate was distinct at $\mathrm{pH}$ 7.0. Qu et al. [14] demonstrated indole could eliminate almost $90 \%$ by the strain SHE at $\mathrm{pH}$ 4.0-9.0. White rot fungus and $P S$ aeruginosa were reported to degrade indole at $\mathrm{pH}$ 5.0-9.0 $[26,27]$. Besides, Phomopsis liquidambari showed the optimal efficiency to degrade indole at $\mathrm{pH} 4.5$ [13].

3.3. Nitrogen Conversion. The changes of $\mathrm{NH}_{3}-\mathrm{N}, \mathrm{NO}_{3}{ }^{-}$, and $\mathrm{NO}_{2}{ }^{-}$were described in Figure 4(a) when $100 \mathrm{mg} / \mathrm{L}$ indole was absolutely removed within $24 \mathrm{~h}$ by the strain L1 in the MSM medium appended with $100 \mathrm{mg} / \mathrm{L}\left(\mathrm{NH}_{4}\right)_{2} \mathrm{SO}_{4}$. At the same time, the initial $\mathrm{NH}_{3}-\mathrm{N}$ decreased from $252.29 \mathrm{mg} / \mathrm{L}$ to $220.65 \mathrm{mg} / \mathrm{L}$ within $15 \mathrm{~h}$, showing the microbial utilization of only about $31.64 \mathrm{mg} / \mathrm{L}$. While the removal efficiency of indole was decreased, the concentration of $\mathrm{NH}_{3}-\mathrm{N}$ was increased after $15 \mathrm{~h}$. Theoretically, $\mathrm{NO}_{3}{ }^{-}$could be $90.13 \mathrm{mg} / \mathrm{L}$ $(40.09 \mathrm{mg} / \mathrm{L}$ from ammonia nitrogen and $50.04 \mathrm{mg} / \mathrm{L}$ from indole), if all the nitrogen source was converted into $\mathrm{NO}_{3}{ }^{-}$. However, $\mathrm{NO}_{3}{ }^{-}$was measured about 77.70 86.31 mg/L after $15 \mathrm{~h}$, and $\mathrm{NO}_{2}{ }^{-}$was not detected. According to Claus and Kutzner's reports, some nitrogen could be utilized to synthesize the intracellular substances [16]. Therefore, indole-N may be partially converted to $\mathrm{NH}_{3}-\mathrm{N}$ and then to $\mathrm{NO}_{3}{ }^{-}$by Acinetobacter pittii L1. 

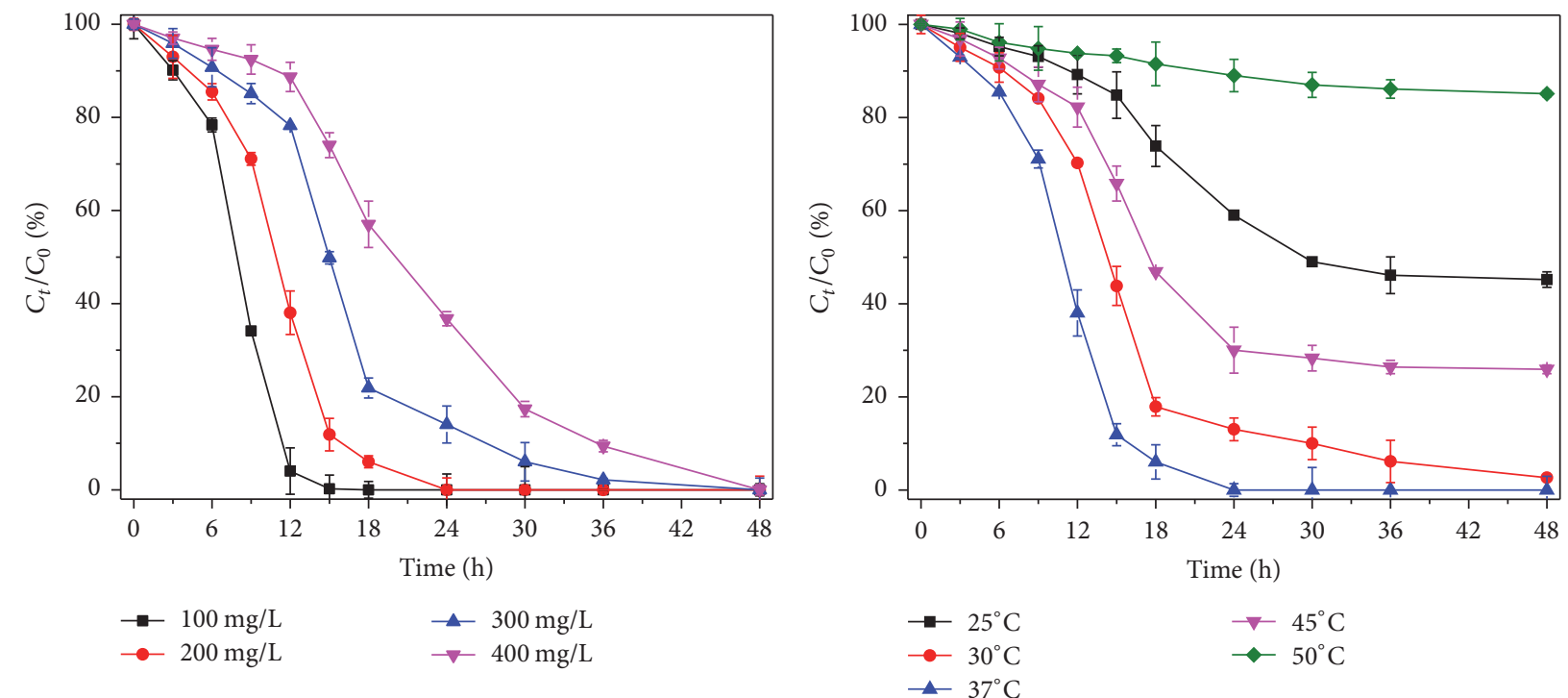

(a)

(b)

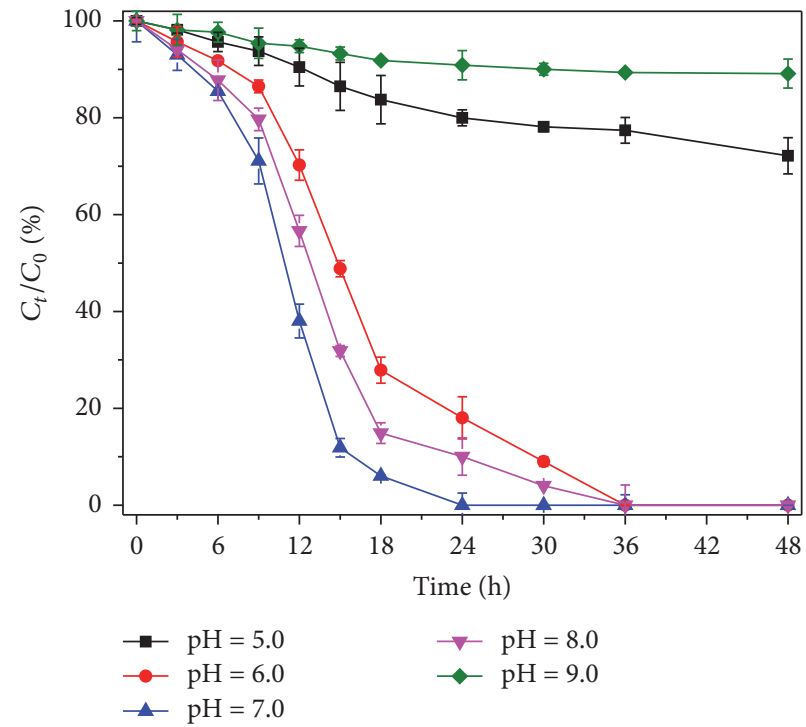

(c)

FiguRE 3: Different biodegrading efficiencies affected by the initial indole concentrations (a), temperatures (b), and $\mathrm{pH}$ values (c) in batch culture and the error bar value stand for the standard deviation of the triplicate.

3.4. Organic Carbon Changes. TC, TOC, and IC were investigated when $100 \mathrm{mg} / \mathrm{L}$ indole was biodegraded. As shown in Figure 4(b), the initial TOC $77.34 \mathrm{mg} / \mathrm{L}$ (similar to the theoretical value of $78.17 \mathrm{mg} / \mathrm{L}$ ) was decreased to $15.37 \mathrm{mg} / \mathrm{L}$ at $24 \mathrm{~h}$, but IC reached $8.94 \mathrm{mg} / \mathrm{L}$ at $12 \mathrm{~h}$ in the same way and decreased afterwards. It was demonstrated that some organic carbons were transferred to $\mathrm{H}_{2} \mathrm{CO}_{3}$ at first and then to $\mathrm{CO}_{2}$ during the indole biodegradation. Figure 4(c) showed the removal efficiency of indole, pyridine, quinoline, and phenol by the strain L1. All the compounds could be degraded by Acinetobacter pittii L1 to some extent: indole and quinoline could be degraded completely within $48 \mathrm{~h}$, $55.81 \%$ of phenol could be removed, and only $20 \%$ of pyridine was wiped over. Both indole and quinoline are structurally benzene-condensed heterocyclic compounds, but pyridine is a monocyclic compound. It was shown that the strain L1 was good at degrading condensed heterocyclic compounds, presumably because of the crucial metabolizing enzymes in the microbe.

3.5. Analysis of the Metabolic Pathways. The metabolites of blue, pink, and virescent hues were visible during the indole biodegradation by Acinetobacter pittii L1. LC-MS/MS was performed to detect the metabolites, the prominent molecular ion $[\mathrm{M}-\mathrm{H}]^{-}$peak at $m / z 260.7,180.0$, and 145.9 of the intermediates was, respectively, shown at the retention time of $2.2 \mathrm{~min}, 4.5 \mathrm{~min}$, and $2.1 \mathrm{~min}$, and their formulas and major mass fragmentation values were listed in Table 2. 


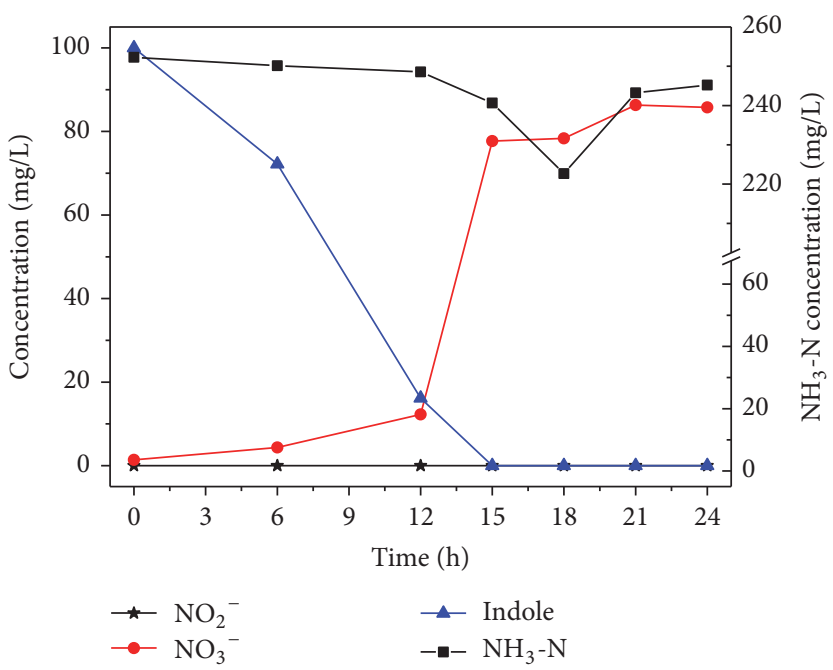

(a)

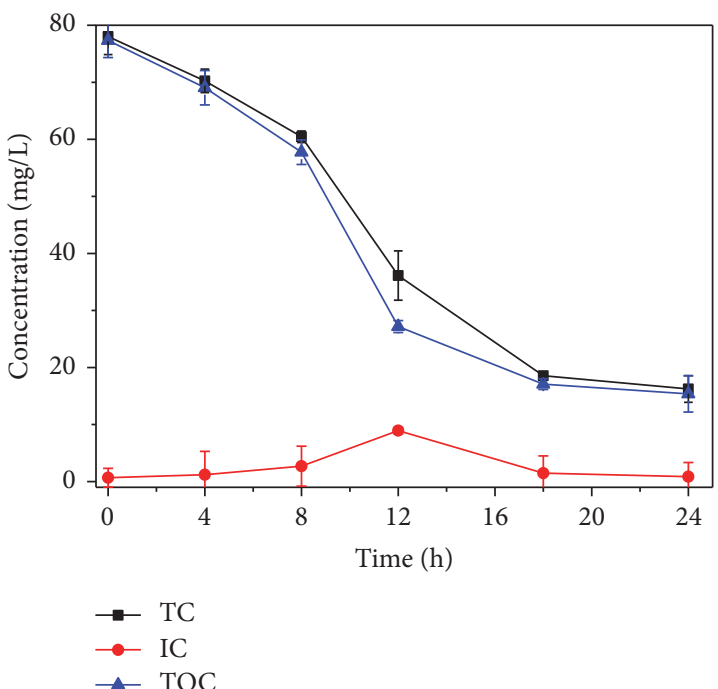

(b)

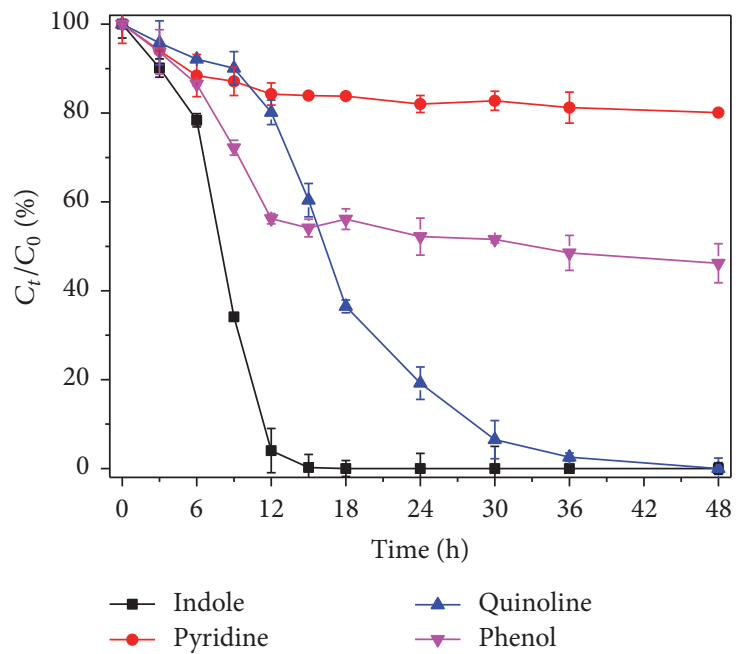

(c)

FIGURE 4: Organic carbon and nitrogen transformations during the indole degradation by Acinetobacter pittii L1, analyzed by the nitrogen source conversions (a), TC, IC, and TOC changes (b), and the different substrate degrading rates (c).

TABLE 2: LC-MS/MS data of the retention time, formula, and major mass fragmentation values to identify the indole biodegrading metabolites.

\begin{tabular}{lcccc}
\hline $\begin{array}{l}\text { Parent ion } \\
{[\mathrm{M}-\mathrm{H}]^{-}}\end{array}$ & $t_{r}(\mathrm{~min})$ & Formula & Major mass fragmentation value $(\mathrm{m} / \mathrm{z})$ & Compounds \\
\hline 260.7 & 2.2 & $\mathrm{C}_{16} \mathrm{H}_{10} \mathrm{~N}_{2} \mathrm{O}_{2}$ & $\begin{array}{c}247.1 / 242.8 / 221.6 / 214.7 / 200.7 / 176.8 / 146.7 / 118.7 \\
\text { Indigo }\end{array}$ \\
180.0 & 2.1 & $\mathrm{C}_{8} \mathrm{H}_{7} \mathrm{NO}_{4}$ & ES-: $152.0 / 135.9 / 124.1 / 107.3$ & $4-(3-$ Hydroxy-1H-pyrrol-2-yl)-2-oxo-but-3-enoic \\
145.9 & 4.5 & $\mathrm{C}_{8} \mathrm{H}_{5} \mathrm{NO}_{2}$ & ES-: $128.3 / 118.2$ & Isatin \\
\hline
\end{tabular}

Figure 5(a) showed the deprotonated molecule at $\mathrm{m} / \mathrm{z}$ 260.7 by the full scan analysis of the samples; the ions scan revealed the major mass spectra fragments at $\mathrm{m} / \mathrm{z} 242.8$ (-18), 221.6 (-39), $214.7(-46), 200.7(-60) 176.8(-84)$, $146.7(-114)$, and $118.7(-142)$. The analysis revealed that the fragmentation ions at $m / z 242.8,176.8,146.7$, and 118.7 corresponded to the losses of $18,44,30$, and $28 \mathrm{Da}$, showing the losses of $\mathrm{H}_{2} \mathrm{O}, \mathrm{CONH}_{2}, \mathrm{NO}$, and $\mathrm{CO}$, respectively, from the parent deprotonated molecule. Considering the molar mass of $262 \mathrm{Da}$, the losses of $\mathrm{CO}, \mathrm{CONH}_{2}, \mathrm{NO}$, and $\mathrm{H}_{2} \mathrm{O}$ from the parent deprotonated molecule, the metabolite of indigo $\left(\mathrm{C}_{16} \mathrm{H}_{10} \mathrm{~N}_{2} \mathrm{O}_{2}\right)$ was confirmed. 


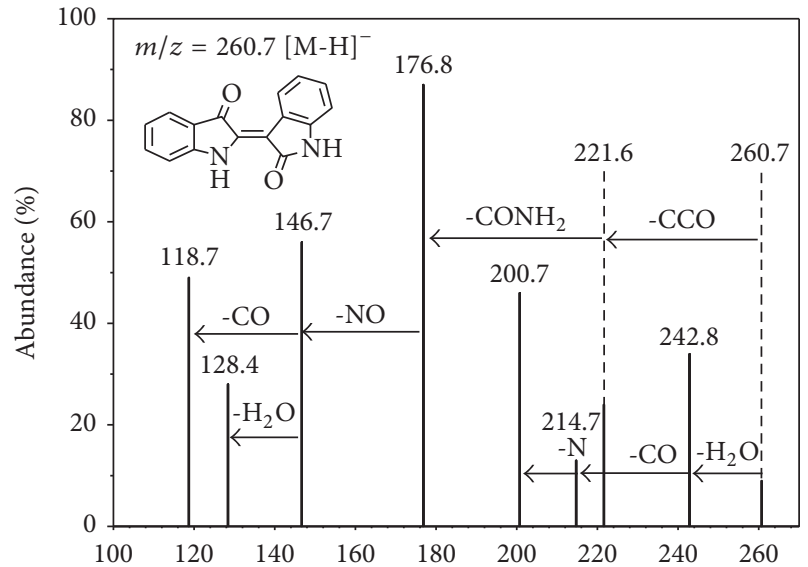

(a)

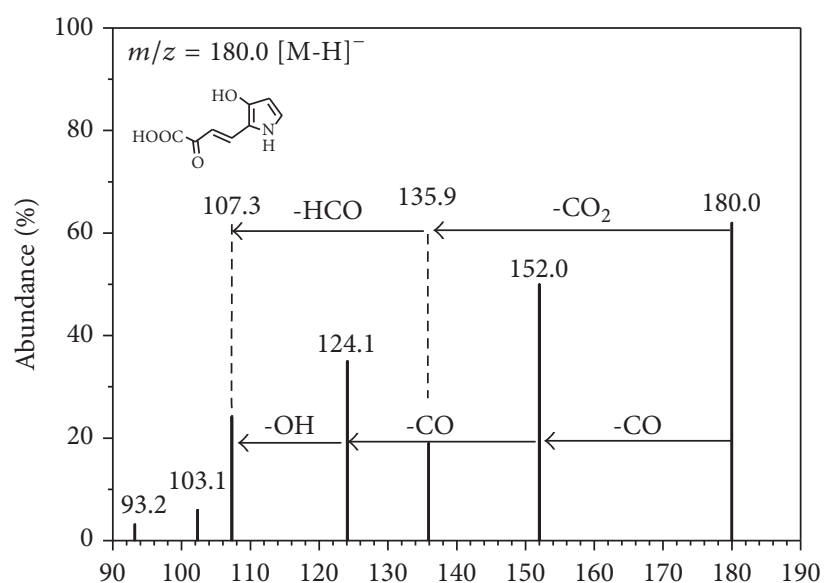

(b)

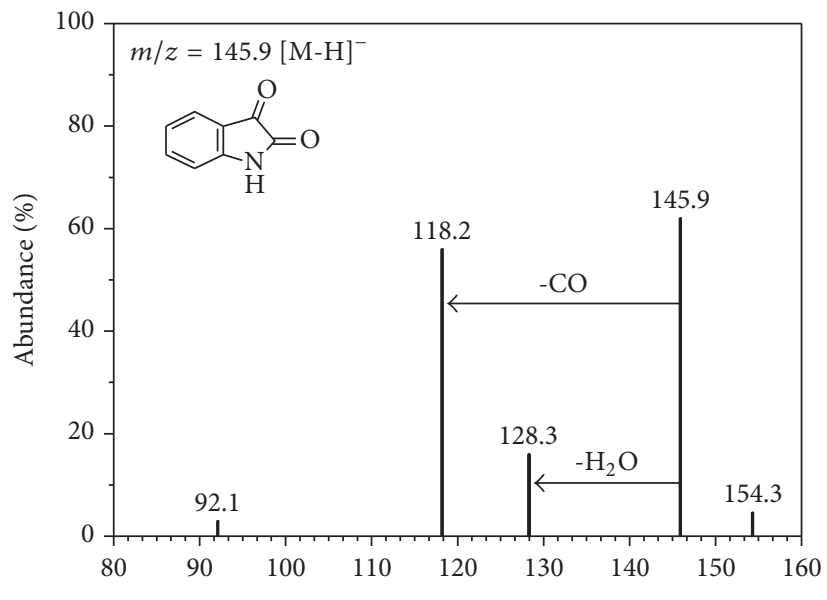

(c)

FIGURE 5: Fragment analysis of the secondary ion mass spectrometry of all the metabolite.

Figure 5(b) showed the deprotonated molecule at $\mathrm{m} / \mathrm{z}$ 180.0 by the $\mathrm{MS}^{2}$ fragmentation spectrum. Four major fragment ions of carboxide (CO), carboxylation $\left(\mathrm{CO}_{2}\right)$, aldehyde $(\mathrm{CHO})$, and hydroxide $(\mathrm{OH})$ could be speculated, according to the mass losses of $28 \mathrm{Da}$ at $\mathrm{m} / z 152.0$ and $124.1,44 \mathrm{Da}$ at $m / z 135.9$, and $29 \mathrm{Da}$ and $17 \mathrm{Da}$ at $m / z$ 107.3. Fukuoka et al. reported that a pyrrole ring could be contained in such compound as the $\mathrm{MS}^{2}$ fragmentation spectrum of ions at $\mathrm{m} / z 180.0$ [28]. Therefore, the intermediate was proposed to be the 4-(3-hydroxy-1H-pyrrol-2-yl)-2-oxo-but-3-enoic acid according to the analytical data and the molecular formula of $\mathrm{C}_{8} \mathrm{H}_{7} \mathrm{NO}_{4}$.

During the indole biodegradation, a pink compound briefly appeared less than $4 \mathrm{~h}$, which was detected in the MS ${ }^{2}$ fragmentation spectrum of ions at $m / z 145.9$ (Figure 5(c)). Additional ion fragments at $m / z 118.2(-28)$ and $128.3(-18)$ indicated the isatin mass losses of $28 \mathrm{Da}$ as $\mathrm{CO}$ and $18 \mathrm{Da}$ as $\mathrm{H}_{2} \mathrm{O}$, respectively. Qu et al. indicated that indoleoxide, hydroxyindole, or 2,3-dihydroxyindole was the metabolites from the aerobic biodegradation of indole and then was oxidized to isatin immediately [14]. Because of the mass losses of $(-28)$ and $(-18)$ detected in the $\mathrm{MS}^{2}$ fragmentation spectrum of ions at $\mathrm{m} / z 145.9$, this metabolite might be derived from the carboxide and hydroxyl additions. Similarly, Zou and Koh observed the same mass losses with the determination of indigotin by LC/ESI-MS/MS at $m / z 242.8$, but the mass loss means the derivation of carboxide addition and phenolic hydroxyl [29].

Nevertheless, other familiar metabolites reported such as indoxyl, oxindole, anthranilate, salicylate and gentisic acid, and hydroxyindole in similar researches were not observed [14]. Therefore, the metabolic pathways of indole degradation by Acinetobacter pittii L1 were speculated (Figure 6), based on the analysis of the identified metabolites in this study.

3.6. Analysis of the Toxicity. To elucidate the ecological risk of the biodegradation products of indole, it is necessary to determine the toxicity evolution of indole contaminated, and the luminescent bacteria Vibrio fischeri were used to assess the changes of the acute toxicity of the compound. Figure 7 represents the inhibition rate, biodegradation rate, and TOC value of $100 \mathrm{mg} / \mathrm{L}$ indole solution fewer than $24 \mathrm{~h}$ of biodegradation. As depicted in Figure 7, the initial inhibition rate of indole was $36.97 \%$ based on the above equation.

As $14.51 \%$ indole was degraded, the Vibrio fischeri inhibition rate decreased dramatically to $16.34 \%$. Subsequently, 


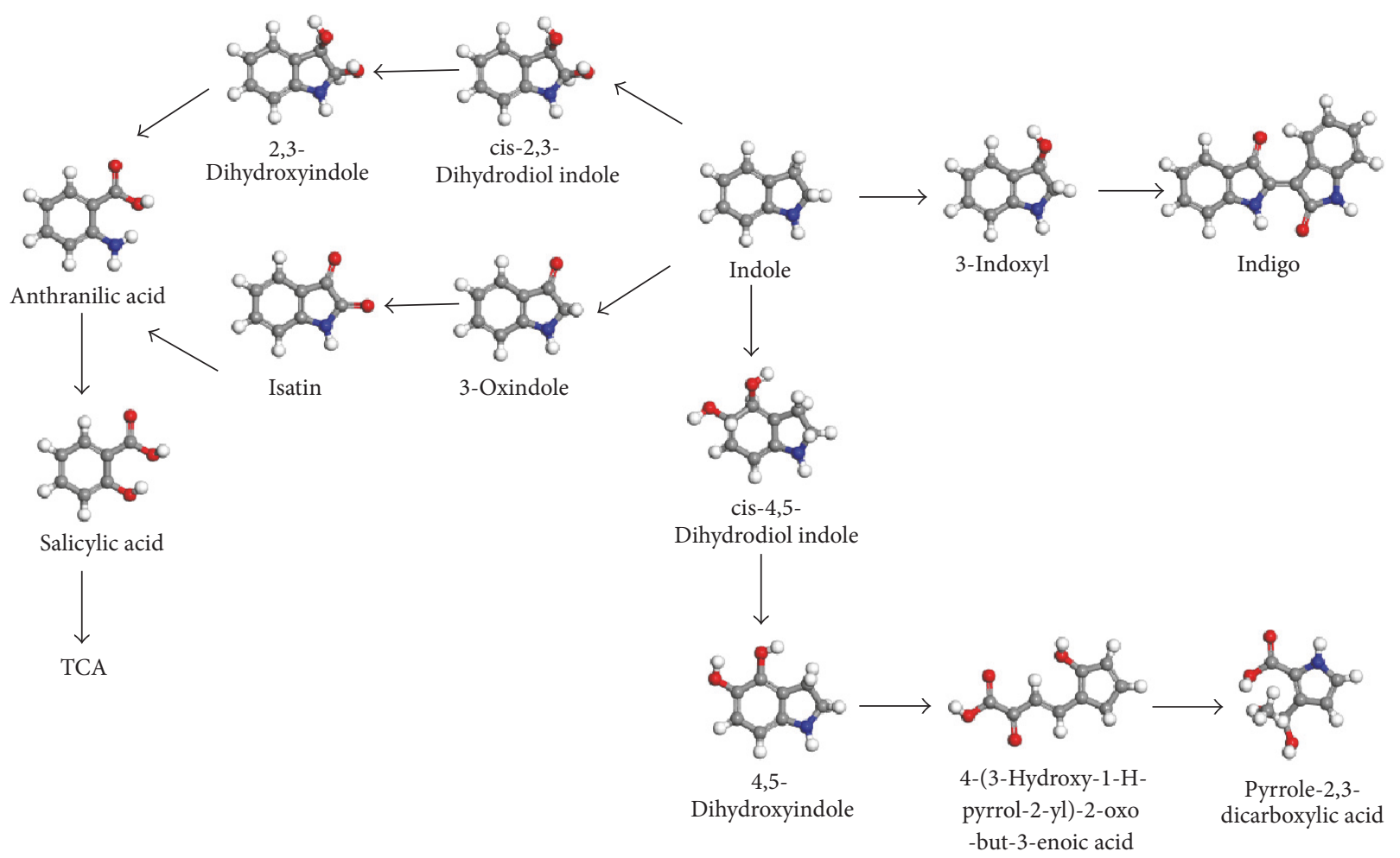

FIGURE 6: Speculated indole metabolic pathway degraded by Acinetobacter pittii L1. The gray, white, blue, and red balls are carbon, hydrogen, nitrogen, and oxygen atoms, respectively.

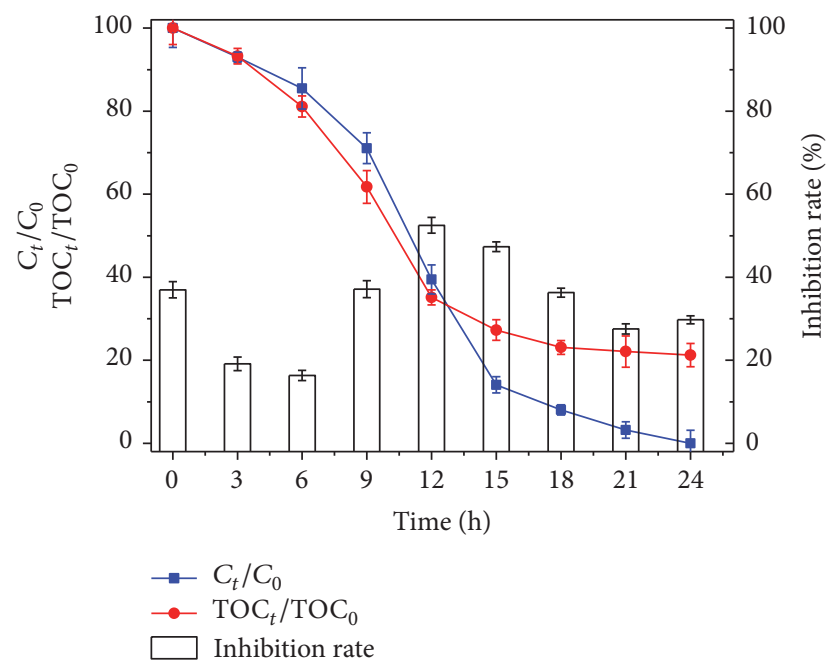

Figure 7: Variation of toxicity by Microtox test, inhibition rate, indole concentration, and TOC during degradation process.

the inhibition rate was quickly increased to $52.49 \%$ when a $\sim 60.53 \%$ degradation rate of indole was obtained. It demonstrated the generation of more toxic products during the degradation of indole. Then the inhibition rate declined dramatically in the second $12 \mathrm{~h}$. The inhibition rate reached an increasing tendency, which means that a new metabolite may be produced in the last. But the final inhibition (28.93\%) was less than the initial inhibition (36.97\%), which means that the metabolites products of indole were ultimately less toxic than the parent compound indole.

In general, the majority of indole was metabolized into intermediate products without the complete mineralization of $\mathrm{CO}_{2}$ and $\mathrm{H}_{2} \mathrm{O}$. Therefore, the ecological risk of indole in engineered systems and ambient aquatic environments must be more closely scrutinized.

\section{Conclusions}

Indole and its derivatives are the representative compounds of NHCs, which are difficult degradable organic pollutants with lethal effect on ecological environment and characteristic odor. An efficient indole degrading Acinetobacter pittii L1 was isolated from a coking wastewater, $400 \mathrm{mg} / \mathrm{L}$ indole in $48 \mathrm{~h}$, which could be thoroughly degraded in the optimum conditions. The removal efficiency of indole decreased after $15 \mathrm{~h}$, but the concentration of $\mathrm{NH}_{3}-\mathrm{N}$ and $\mathrm{NO}_{3}{ }^{-}$increased, showing the change of indole- $\mathrm{N}$, and some organic carbon of indole was likely transferred into $\mathrm{CO}_{2}$ eventually, and the metabolites products of indole were ultimately less toxic than the parent indole. It is shown that the isolated Acinetobacter pittii L1 could eliminate indole effectively and the metabolic pathways were speculated by the analysis of metabolites. Our results elucidated that the high efficiency of degradation ability to degrade indole makes Acinetobacter pittii L1 as an excellent candidate for producing indigo and eliminating NHCs and for printing and dyeing industrials with indole contaminated area. 


\section{Conflicts of Interest}

The authors declare that there are no conflicts of interest regarding the publication of this paper.

\section{Acknowledgments}

This research was funded by the Science and Technology Project of Guangdong Province, China (nos. 2014A020216038 and 2016B020240003), Guangdong Natural Science Foundation (no. 2016A030313695), and the Youth Fund of Guangdong University of Technology (no. 14QNZD006).

\section{References}

[1] S. Mudliar, B. Giri, K. Padoley et al., "Bioreactors for treatment of VOCs and odours - A review," Journal of Environmental Management, vol. 91, no. 5, pp. 1039-1054, 2010.

[2] S.-Y.He, Y.-H. Lin, K.-Y. Hou, and S.-C. J. Hwang, "Degradation of dimethyl-sulfoxide-containing wastewater using airlift bioreactor by polyvinyl-alcohol-immobilized cell beads," Bioresource Technology, vol. 102, no. 10, pp. 5609-5616, 2011.

[3] P. Chen, W. Lv, and Z. Chen, "Phototransformation of mefenamic acid induced by nitrite ions in water: mechanism, toxicity, and degradation pathways," Environmental Science \& Pollution Research International, vol. 22, pp. 1-12, 2015.

[4] X. Hong, X. Zhang, B. Liu, Y. Mao, Y. Liu, and L. Zhao, "Structural differentiation of bacterial communities in indoledegrading bioreactors under denitrifying and sulfate-reducing conditions," Research in Microbiology, vol. 161, no. 8, pp. 687693, 2010.

[5] F. Bak and F. Widdel, "Anaerobic degradation of indolic compounds by sulfate-reducing enrichment cultures, and description of Desulfobacterium indolicum gen. nov., sp. nov.," Archives of Microbiology, vol. 146, no. 2, pp. 170-176, 1986.

[6] M. Frey, C. Stettner, P. W. Paré, E. A. Schmelz, J. H. Tumlinson, and A. Gierl, "An herbivore elicitor activates the gene for indole emission in maize," Proceedings of the National Acadamy of Sciences of the United States of America, vol. 97, no. 26, pp. 1480114806, 2000.

[7] D. Blom, C. Fabbri, E. C. Connor et al., "Production of plant growth modulating volatiles is widespread among rhizosphere bacteria and strongly depends on culture conditions," Environmental Microbiology, vol. 13, no. 11, pp. 3047-3058, 2011.

[8] K. Gai, H. Qi, Y. Zhang, and D. Ma, "Degradation of indole in aqueous solution using contact glow discharge plasma," Journal of Applied Electrochemistry, vol. 40, no. 3, pp. 615-619, 2010.

[9] S. Lin and R. M. Carlson, "Susceptibility of environmentally important heterocycles to chemical disinfection: Reactions with aqueous chlorine, chlorine dioxide, and chloramine," Environmental Science \& Technology, vol. 18, no. 10, pp. 743-748, 1984.

[10] S. Merabet, D. Robert, J.-V. Weber, M. Bouhelassa, and S. Benkhanouche, "Photocatalytic degradation of indole in UV/ TiO2: Optimization and modelling using the response surface methodology (RSM)," Environmental Chemistry Letters, vol. 7, no. 1, pp. 45-49, 2009.

[11] S. Merabet, A. Bouzaza, and D. Wolbert, "Photocatalytic degradation of indole in a circulating upflow reactor by $\mathrm{UV} / \mathrm{TiO}_{2}$ process-Influence of some operating parameters," Journal of Hazardous Materials, vol. 166, no. 2-3, pp. 1244-1249, 2009.
[12] B.-H. Tuo, J.-B. Yan, B.-A. Fan, Z.-H. Yang, and J.-Z. Liu, "Biodegradation characteristics and bioaugmentation potential of a novel quinoline-degrading strain of Bacillus sp. isolated from petroleum-contaminated soil," Bioresource Technology, vol. 107, pp. 55-60, 2012.

[13] Y. Chen, X.-G. Xie, C.-G. Ren, and C.-C. Dai, "Degradation of N-heterocyclic indole by a novel endophytic fungus Phomopsis liquidambari," Bioresource Technology, vol. 129, pp. 568-574, 2013.

[14] Y. Qu, E. Shen, Q. Ma et al., "Biodegradation of indole by a newly isolated Cupriavidus sp. SHE," Journal of Environmental Sciences, vol. 34, pp. 126-132, 2015.

[15] Y. Qu, B. Xu, X. Zhang et al., "Biotransformation of indole by whole cells of recombinant biphenyl dioxygenase and biphenyl2,3-dihydrodiol-2,3-dehydrogenase," Biochemical Engineering Journal, vol. 72, pp. 54-60, 2013.

[16] G. Claus and H. J. Kutzner, "Degradation of indole by Alcaligenes spec," Systematic and Applied Microbiology, vol. 4, no. 2, pp. 169-180, 1983.

[17] F. Wang, P. Chen, Y. Feng et al., "Facile synthesis of N-doped carbon dots/g-C3N4 photocatalyst with enhanced visible-light photocatalytic activity for the degradation of indomethacin," Applied Catalysis B: Environmental, vol. 207, pp. 103-113, 2017.

[18] Z. H. M. Yadzir, M. Y. Shukor, A. Ahmad, M. S. Nazir, S. M. U. Shah, and M. A. Abdullah, "Phenol removal by newly isolated Acinetobacter baumannii strain Serdang 1 in a packed-bed column reactor," Desalination and Water Treatment, vol. 57, no. 28, pp. 13307-13317, 2016.

[19] S. K. Karn and X. Pan, "Role of Acinetobacter sp. in arsenite As(III) oxidation and reducing its mobility in soil," Chemistry and Ecology, vol. 32, no. 5, pp. 460-471, 2016.

[20] S. Silambarasan and A. S. Vangnai, "Biodegradation of 4-nitroaniline by plant-growth promoting Acinetobacter sp. AVLB2 and toxicological analysis of its biodegradation metabolites," Journal of Hazardous Materials, vol. 302, pp. 426-436, 2016.

[21] M. Song, L. Jiang, D. Zhang et al., "Bacteria capable of degrading anthracene, phenanthrene, and fluoranthene as revealed by DNA based stable-isotope probing in a forest soil," Journal of Hazardous Materials, vol. 308, pp. 50-57, 2016.

[22] J. Wang, X. Zhang, J. Fan, Z. Zhang, Q. Ma, and X. Peng, "Indigoids biosynthesis from indole by two phenol-degrading strains, pseudomonas sp. PI1 and Acinetobacter sp. PI2," Applied Biochemistry and Biotechnology, vol. 176, no. 5, pp. 1263-1276, 2015.

[23] P. Katapodis, M. Moukouli, and P. Christakopoulos, "Biodegradation of indole at high concentration by persolvent fermentation with the thermophilic fungus Sporotrichum thermophile," International Biodeterioration \& Biodegradation, vol. 60, no. 4, pp. 267-272, 2007.

[24] B. Yin, J.-D. Gu, and N. Wan, "Degradation of indole by enrichment culture and Pseudomonas aeruginosa Gs isolated from mangrove sediment," International Biodeterioration \& Biodegradation, vol. 56, no. 4, pp. 243-248, 2005.

[25] G. M. M. Moghanloo, E. Fatehifar, S. Saedy, Z. Aghaeifa, and H. Abbasnezhad, "Biological oxidation of hydrogen sulfide in mineral media using a biofilm airlift suspension reactor," Bioresource Technology, vol. 101, no. 21, pp. 8330-8335, 2010.

[26] D. Ren, X. Zhang, and K. Yan, "Studies on the degradation of indole using white rot fungus," Fresen Environ Bull, vol. 15, pp. 1238-1243, 2006.

[27] N. R. Krieg, J. T. Staley, D. R. Brown et al., Bergey's Manual of Systematic Bacteriology, Springer, 2011. 
[28] K. Fukuoka, K. Tanaka, Y. Ozeki, and R. A. Kanaly, "Biotransformation of indole by Cupriavidus sp. strain KK10 proceeds through N-heterocyclic- and carbocyclic-aromatic ring cleavage and production of indigoids," International Biodeterioration \& Biodegradation, vol. 97, pp. 13-24, 2015.

[29] P. Zou and H. L. Koh, "Determination of indican, isatin, indirubin and indigotin in Isatis indigotica by liquid chromatography/electrospray ionization tandem mass spectrometry," Rapid Communications in Mass Spectrometry, vol. 21, no. 7, pp. 12391246, 2007. 

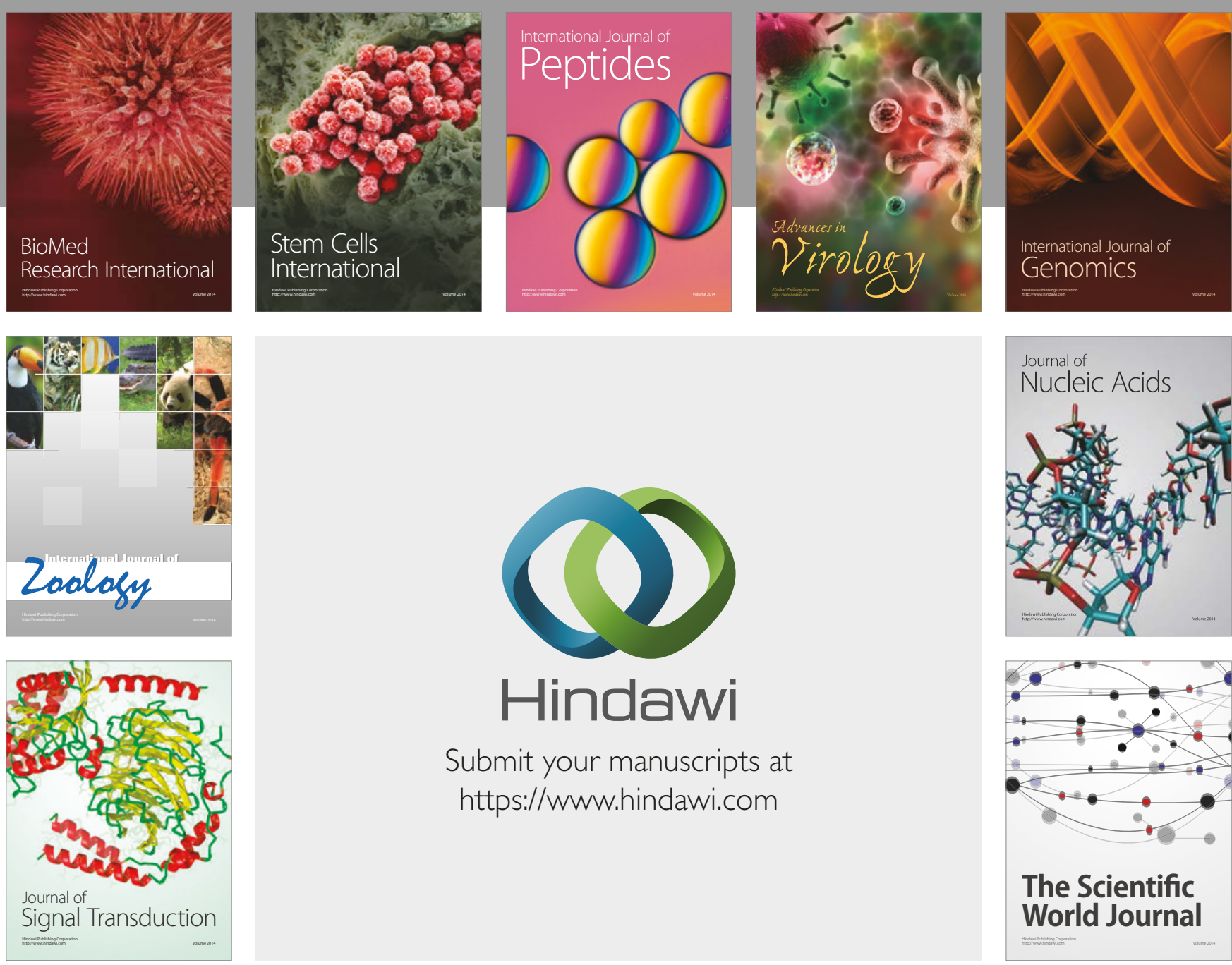

Submit your manuscripts at

https://www.hindawi.com
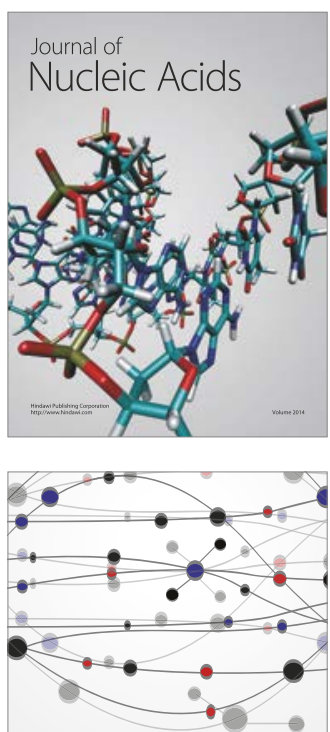

The Scientific World Journal

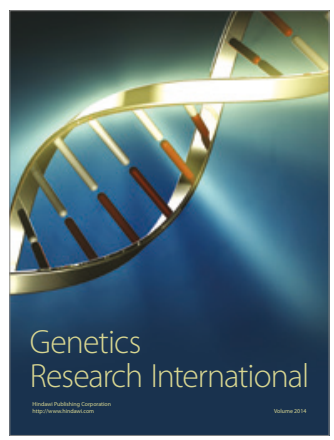

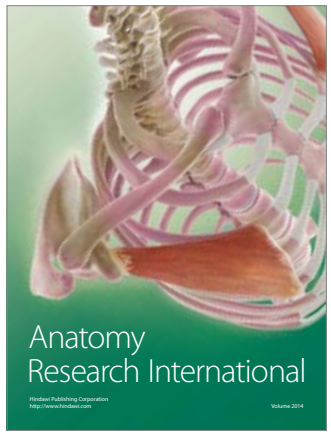

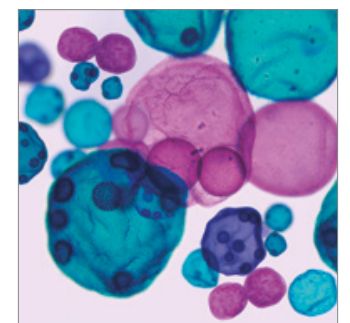

International Journal of Microbiology
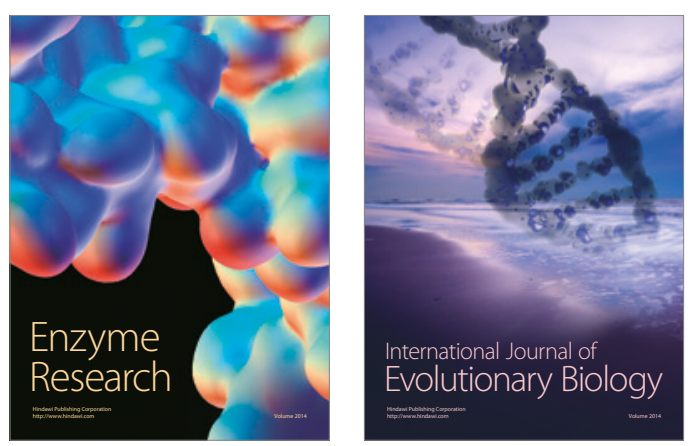
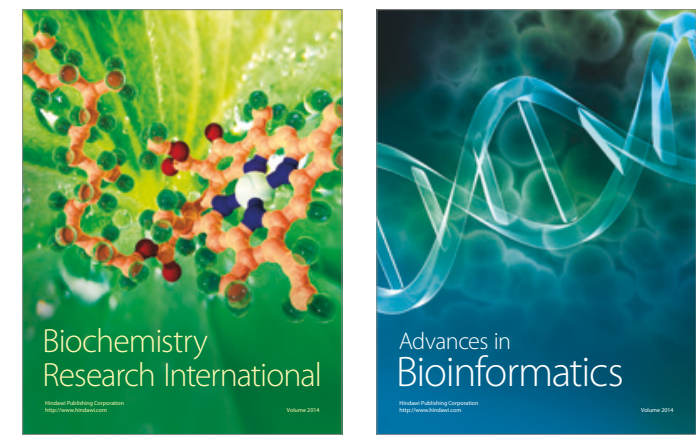

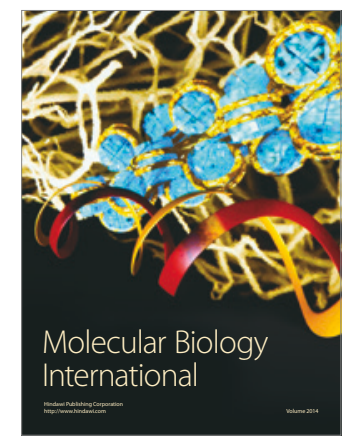

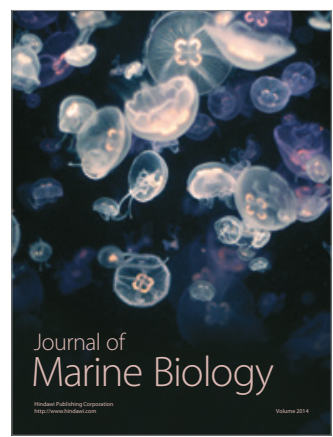

